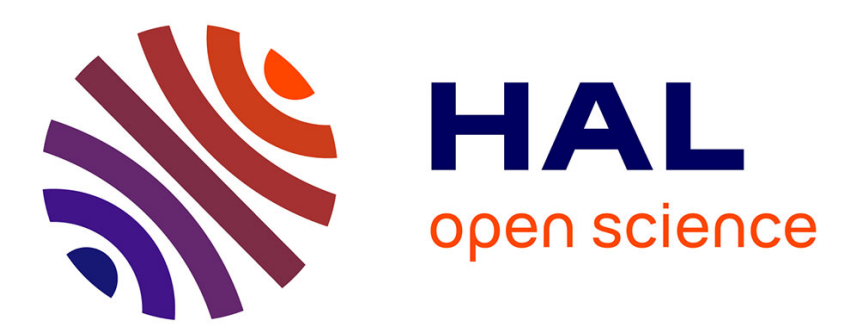

\title{
Cathodic carbon peroxidation process. Surface modifications through oxygen bonding
}

Jacques Simonet

\section{To cite this version:}

Jacques Simonet. Cathodic carbon peroxidation process. Surface modifications through oxygen bonding. Electrochemistry Communications, 2013, 34, pp.223-227. 10.1016/j.elecom.2013.06.005 . hal00915143

\section{HAL Id: hal-00915143 \\ https://hal.science/hal-00915143}

Submitted on 6 Dec 2013

HAL is a multi-disciplinary open access archive for the deposit and dissemination of scientific research documents, whether they are published or not. The documents may come from teaching and research institutions in France or abroad, or from public or private research centers.
L'archive ouverte pluridisciplinaire HAL, est destinée au dépôt et à la diffusion de documents scientifiques de niveau recherche, publiés ou non, émanant des établissements d'enseignement et de recherche français ou étrangers, des laboratoires publics ou privés. 


\title{
Cathodic Carbon Peroxidation Process. Surface Modifications Through Oxygen Bonding.
}

\author{
Jacques Simonet* \\ Equipe MaCSE, UMR 6226, Université de Rennes, Campus de Beaulieu, 35042 Rennes Cedex, France.
}

\begin{abstract}
The reduction of oxygen of the air at carbon electrodes in organic aprotic polar solvents in the presence of organic electrophiles such as alkyl iodides may reveal the formation of films of surface-attached alkyl peroxides. Electrochemical charge of carbons (glassy carbon, graphite, industrial coke) in the presence of tetraalkylammonium salts TAAX permits the building of poly-nucleophilic materials that may spontaneously react with air during the work up. This way, a TAA ${ }^{+}$hydroperoxydate layer immobilized at the solid surface can be obtained. The existence of such layers is supported by the reaction with a large number of organic electrophiles in order to generate attached organic peroxides capable (i) to be cleaved (two-electron scission of the O-O bond) or (ii) to obtain by grafting of $\pi$-acceptors and/or $\pi$ donors, specific redox responses at those modified surfaces. Such modification procedure (essentially green: electrolytic solutions are totally re-usable with the main reagent being air) is expected to yield a material easily transformed into a stable poly-hydroxylated solid. At this stage, a large panel of simple chemical transformations can be imagined from classical organic and inorganic chemistry.
\end{abstract}

Key words: Carbon cathodes; Carbon functionalization; Oxygen grafting; Peroxides; Hydroperoxides.

Corresponding author: jacques.simonet@univ-rennes1.fr

\section{Introduction}

Glassy carbon (GC) appears as a cheap and almost universal material to carry out electrolyses within the cathodic range [1-3]. This material was reported to contain graphite-like nano-structures and then could be seen in most of the cases (depending on its mode of preparation) as a complex solid containing mixtures of micro-graphitized and fullerenized zones where $\mathrm{sp}^{2}$ carbon atoms predominate [4-6] within carbon reticulated zones.

In the course of a quite large series of electro-organic reactions achieved at all allotropic varieties of carbon surfaces, organic layer depositions are mainly expected to occur via additions of intermediate free radicals to the emerging carbon bulk, thus revealing high importance of these 
unsaturated impurities (acting as radical traps) present in most of rough carbons. As a matter of fact, radical grafting was reported to occur within the cathodic range with electroactive salts like aryl diazonium salts [7]. Additionally, activated carbon-halogen bonds (allylic, benzylic and propargylic halides) were reported to afford free radicals [8-9] and could also be used for convenient surface modifications by unsaturated organic moieties enabling secondary grafting processes. The use of catalysts (transition metals in sub-molar concentration preliminarily deposited at the GC surface) could be efficiently used for formation of dense layers via the immobilization of functionalized alkyl radicals [10].

In the aim of going further in diversifying and innovating in surface chemical modification of carbons, it has been very recently proposed to consider the electrochemical cathodic charge of carbons (well known in the field of electricity storage, such le reversible insertion of $\mathrm{Li}^{+}$inside the graphite plans) [11] and therefore creating nucleophilic micro-centers inside and at its surface by employing non-electrophilic cations such as tetraalkylammonium $\mathrm{TAA}^{+}$. This proposal, developed during 2-3 recent years,could enlarge possibilities of surface modifications if electrophilic species are present concomitantly (or after) the charge in the electrolytic bulk. Thus, GC under cathodic polarization at $\mathrm{E}<-1.7 \mathrm{~V}$ vs. $\mathrm{Ag} / \mathrm{AgCl}$ appears to yield nucleophilic species [12] capable to produce, to a large extent, interfacial reactions. Therefore, the reactivity of GC interface (electron transfer(s) versus $\mathrm{S}_{\mathrm{N}}$ 2-like reactions) toward organic derivatives featuring some electrophilic behavior is worth being re-considered.

The present communication reports on new chemical possibilities based on preliminary charging carbon (by cathodic reduction of the material at fixed potentials between $-1.8 \mathrm{~V}$ and $-2.2 \mathrm{~V}$ ) in polar organic solvents in the presence of TAAX salts. The method lies on the electrophilicity of di-oxygen towards negatively charged carbon atoms. The approach resembles to the reaction of $\mathrm{O}_{2}$ toward Grignard reagents $\mathrm{RMgX}$ (or $\mathrm{ArMgX}$ ) already reported to afford the formation of peroxides $\mathrm{R}-\mathrm{O}-\mathrm{O}$ $\mathrm{MgX}$ and hydroperoxides [13]. In the present report, the reduced carbon is allowed to react with dioxygen (contact with air during the work-up) permitting to create hydro-peroxide layers at the surface. These preliminary formed poly-nucleophiles, through their reactions with a large panel of electrophiles, open the route to a facile and quite certainly general method for modification of carbon surfaces. Generation of such layers and their specific electrochemistry and chemical transformations are preliminarily presented.

\section{Experimental}


Voltammetry was essentially carried out in $0.1 \mathrm{M}$ solutions of tetraalkylammonium salts (TAAX) such as tetramethylammonium $\left(\mathrm{TMABF}_{4}\right)$ and tetrabutylammonium $\left(\mathrm{TBABF}_{4}\right)$ tetrafluoroborates in upper grade dimethylformamide (DMF) and acetonitrile (AN). Experiments described in this work needed no special treatment of electrolytic solutions.

Potentials are referred to the aqueous $\mathrm{Ag} / \mathrm{AgCl} / \mathrm{KCl}_{\text {(sat) }}$. Voltammetric and coulometric measurements were performed using three-electrode cells separated with a fritted glass. The electrochemical instrumentation has been previously reported [12].

Glassy carbon (GC) electrodes used as substrates had geometric area of 0.8 and $7 \mathrm{~mm}^{2}$. All those carbon samples were purchased from Tokai Carbon $\mathrm{C}^{\circ}$ (code: GC Rod).

Prior to being electrochemically charged (cell with a separator) at potential between -2.0 and -2.3 V in DMF containing $\mathrm{TMABF}_{4}$, electrodes and large plates (coming from CarboneLorraine, vitrified at 1500 or $2500{ }^{\circ} \mathrm{C}$ ) were carefully polished first with silicon carbide paper (Struers 500) and then with Norton polishing paper (type 02). Then, carbon samples were placed in the contact of air and sonicated for $5 \mathrm{~min}$ in water and rinsed three times with acetone.

Chemicals used in this paper are essentially organic electrophiles (derived from primary alkyl iodides) such as n-octyl, n-decyl, and n-dodecyl iodides. Marked electrophiles like $\omega$ iodohexyl-1-ferrocene and 4-nitrobenzylbromide were also employed. Most of them were purchased from Aldrich. The ferrocene marker was synthesized according to a process already reported [12].

\section{Results}

\subsection{Voltammetric evidence of peroxidation of carbon surfaces.}

Figure 1 (curves A and B) exhibits the possibility generation (via voltammetry after a hold at $-1.0 \mathrm{~V}$, starting the scan, in AN or DMF containing a TAAX salt) of superoxide capable of in situ reacting with a primary iodo-alkane RI. When potential hold at the GC electrode and argon bubbling concomitantly occur during a time long enough to lead to the total disappearance of air from the cell and possibly disperse into the liquid bulk all the alkylperoxide R-O-O-R formed the in surrounding of the electrode surface, we may observe an intriguing feature where a pre-step can be obtained during the first scan and then disappears in the course of the second. The main steps shown in A1 and B obtained with 1iodododecane and 1-iododecane, respectively, in the course of the second scan fit with the 
reduction steps of those RIs in deaerated solutions. The bell-shaped pre-peak $\left(E_{p}=-1.38 \mathrm{~V}\right)$ especially observed with 1-iodododecane (A1) strongly suggests that an electroactive intermediate reacted with the surface organized in SAMs implying dodecyl chains. This does not appear with shorter RIs. It is expected that this intriguing pre-step could partly correspond to the reduction of a layer attached onto carbon by grafting of free alkyl-peroxo radicals issued from mono-alkylation of superoxide (Scheme 1, equation 2). The attachment (competing with a second electron transfer) to the carbon surface could correspond to equation 4. In order to verify this hypothesis, an RI marked with ferrocene ( $\omega$-iodo- $n$ hexylferrocene) was tested (Figure 1, curves C). Under such conditions (partial pressure of dioxygen in the presence of an excess of RI, the reduction of $\mathrm{O}_{2}$ turns being irreversible (equations 1-3)) while a sole scan until -1.0 V clearly permits to establish, after sonication of the working electrode, the attachment of ferrocene to the carbon surface (Curve C3) that permits estimating the superficial ferrocene concentration as $\Gamma_{\mathrm{Fe}}=1.2 \times 10^{-9} \mathrm{~mol} \mathrm{~L}^{-1}$ which could correspond to a peroxo-monolayer at a rather rough carbon interface. In contrast, similar calculations made on the bell-shape pre-peak (displayed in A2, Figure 1), revealed high values of the coverage $\left(\Gamma_{\mathrm{OOR}}=2.1 \times 10^{-8} \mathrm{~mol} \mathrm{~L}^{-1}\right)$ by electroactive layer; this value is probably overestimated due to the presence of ROOR at the electrode surface prepared without sonication. 


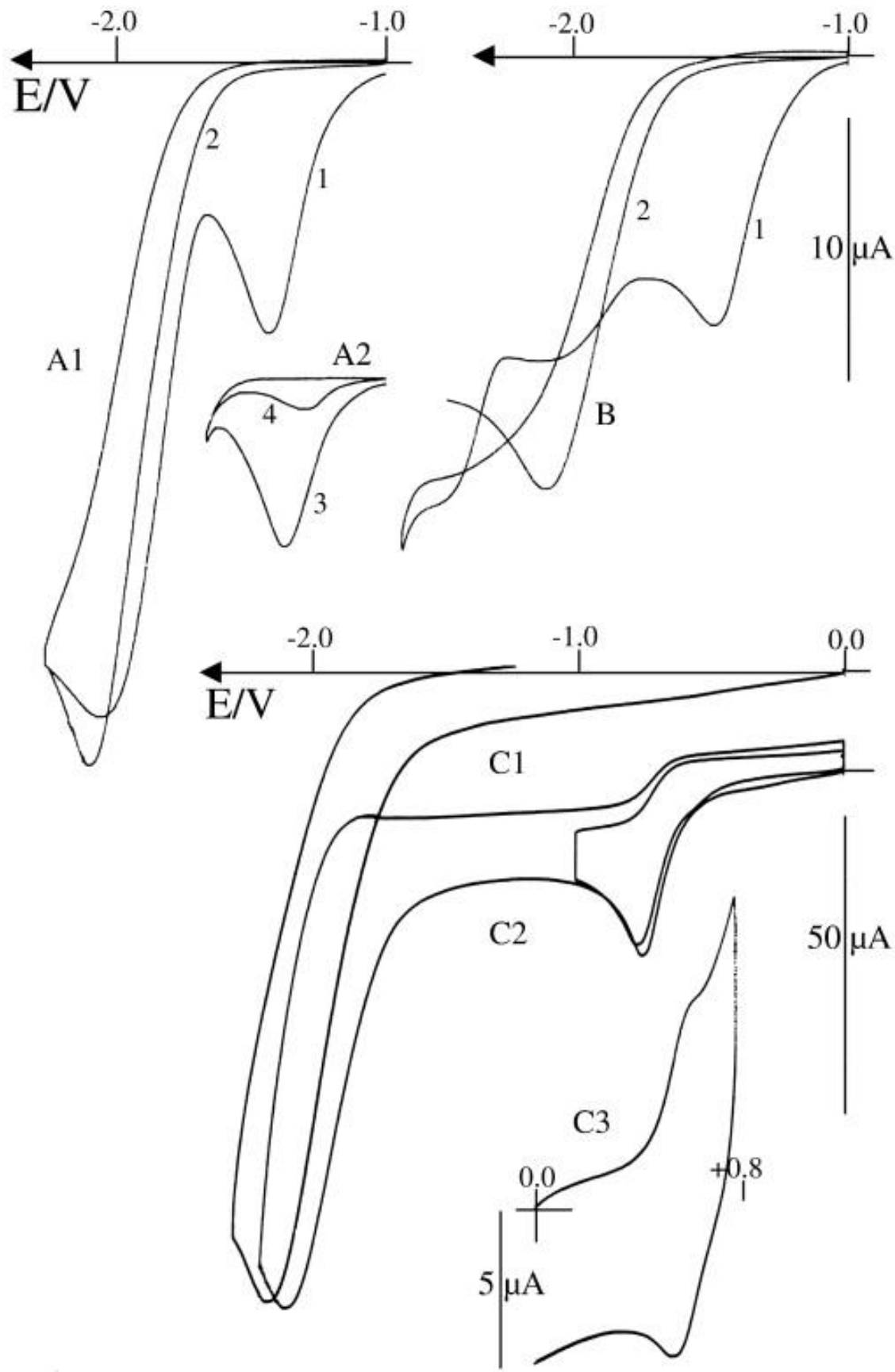

Fig. 1. A) and B), Voltammetry of 1-iodoalkanes at GC electrodes in AN + $\mathrm{TBAPF}_{6}$ scan rate: $50 \mathrm{mV} \mathrm{s}^{-1}$. Surface areas of used electrode: $0.8 \mathrm{~mm}^{2}$. Exhibited scans are those of 1iododecane in A $\left(8.5 \mathrm{mmol} \mathrm{L}^{-1}\right)$ and 1-iodododecane in $\mathrm{B}\left(5.6 \mathrm{mmol} \mathrm{L}^{-1}\right)$. Such voltammetric responses are only obtained when the potential $(-1 \mathrm{~V})$ is applied concomitantly with the start of the argon bubbling until a total de-aeration of the electrolytic solution. C) Voltammetry of $\mathrm{Fc}_{-} \mathrm{C}_{6}-\mathrm{I}\left(7.4 \mathrm{mmol} \mathrm{L}^{-1}\right)$ as electrophile in $\mathrm{DMF}+\mathrm{TBABF}_{4}$. Apparent surface area of electrodes: $7 \mathrm{~mm}^{2}$. In $\mathrm{C}$ 1, electrode response in the absence of di-oxygen in the solution. In $\mathrm{C} 2$, the same solution with a partial pressure of di-oxygen. In $\mathrm{C} 3$, anodic response in a solution free of $\mathrm{Fc}_{-} \mathrm{C}_{6}$-I after one single scan between 0 and $-1 \mathrm{~V}$. 


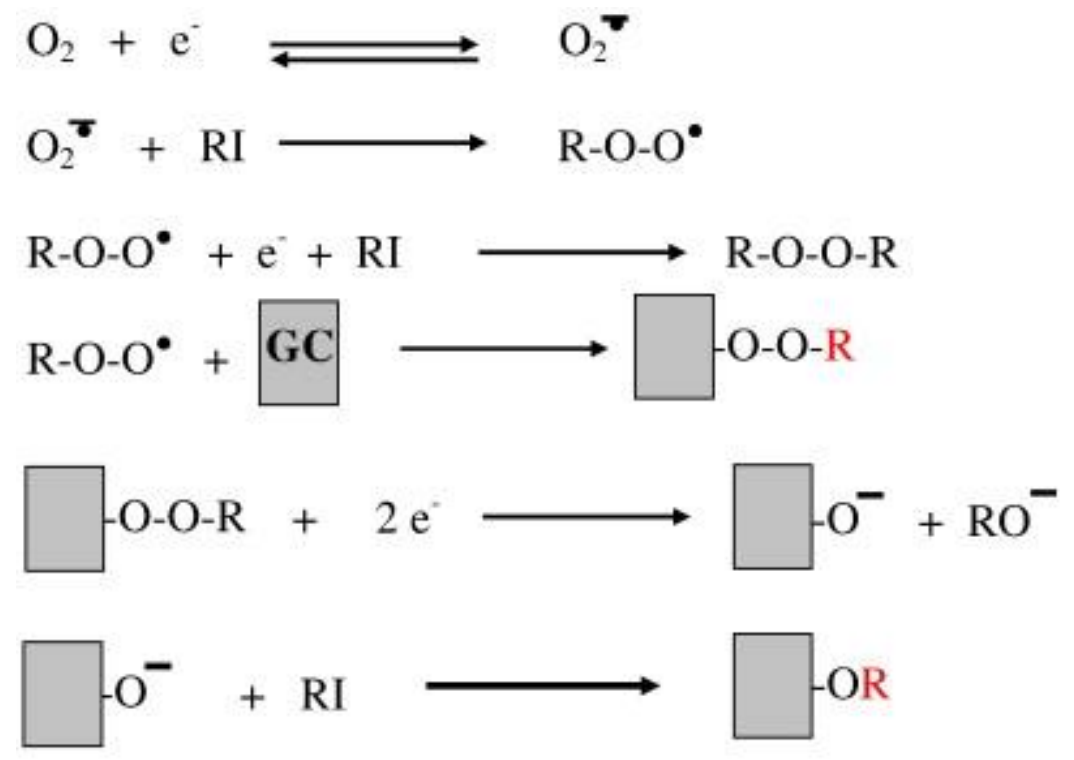

Independently, an indirect peroxidation of carbon can be also achieved via $\mathrm{GC}$ reduction at $-2.2 \mathrm{~V}$ in aprotic solvents followed (work up) by contact with air:

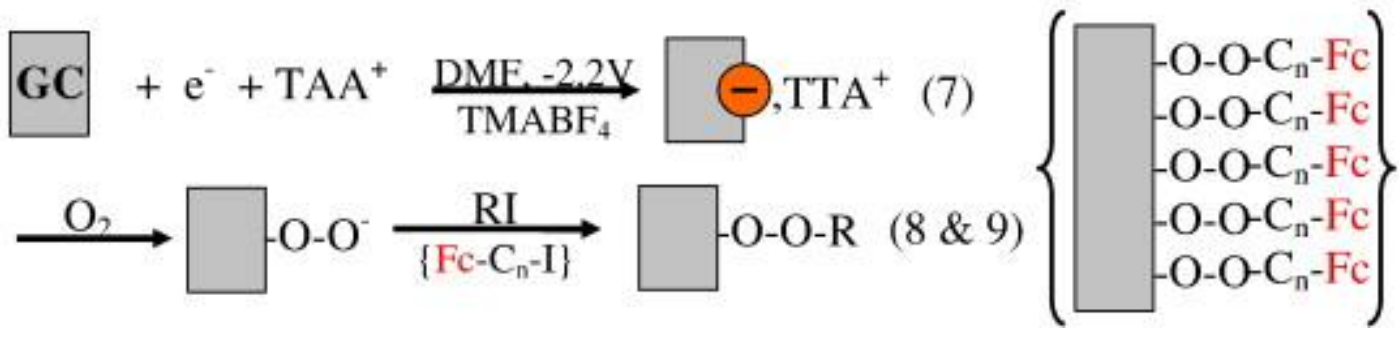

Scheme 1. Main reactions provoked by contact of oxygen to charged carbon cathodes in the presence of alkyl iodides RIs as electrophiles.

\subsection{Use of cathodically charged carbon electrodes as strongly nucleophilic materials.}

From the preliminary results described in $\$ 3.1$, it was searched to check the reactivity of oxygen in contact with cathodically charged carbon (graphite, glassy carbon, industrial coke) simply achieved in DMF saturated with tetramethylammonium tetrafluoroborate $\left(\mathrm{TMABF}_{4}\right)$. The preference of $\mathrm{TMA}^{+}$has been already discussed and permits a better charge of graphite and graphite impurities contained in glassy carbon and cokes. The nucleophilic ability of such materials was applied for immobilizing carbon dioxide and functionalized alkyl halides under oxygen-free atmospheres. Chemically, the electrophilicity of di-oxygen towards Grignard reagents is well established and certainly prompts us to test the reaction \{charged $\mathrm{GC}+\mathrm{O}_{2}$ \} Under these conditions, instead the formation of $\mathrm{R}-\mathrm{O}-\mathrm{O}^{-}$(mainly leading to hydroperoxides in the case of Grignard reagents), the expected process would be oriented toward the surface 
coverage with GC-O-O- (or with GC-O-O-R, RX being any electrophile added after the oxidation). Such coverage is very fast to form during the work-up (rinsing of the charged material or/and its sonication in water or dipping into a solution containing the RX compound). The process is actually easy, general, and opens large possibilities of carbon modifications especially if the electrochemical scission of the O-O bond is considered. Moreover, the process could be considered as green since the solution allowing the carbon charge is reusable and quite certainly, many electrolytes could be proposed for the peroxidation of the surface.

The numerous foreseeable possibilities are shortly evoked in Figure 2. Precise experimental conditions are underlined in its caption. Therefore, in A, the GC electrode first charged and then exposed to air (equation 7 and 8, Scheme 1), reacts fast with the primary alkyl iodide (reaction 8) to give a large reduction step a $\left(\mathrm{E}_{\mathrm{p} / 2}=-1.4 \mathrm{~V}\right)$ almost disappearing from the second scan (in b) that can be identified as cathodic scission of the grafted alkyl-peroxide. Lastly after two or three scans, only one step c remains that corresponds to the two-electron cleavage of the RI. Very similarly, in B and C at graphene and graphite surfaces, the steps at $1.4 \mathrm{~V}$ can be assigned to the scission of the O-O bond. Differences bound to the nature of surfaces (graphene in B and graphite in C) are due to the catalytic processes specific of these charged interfaces towards RIs. 

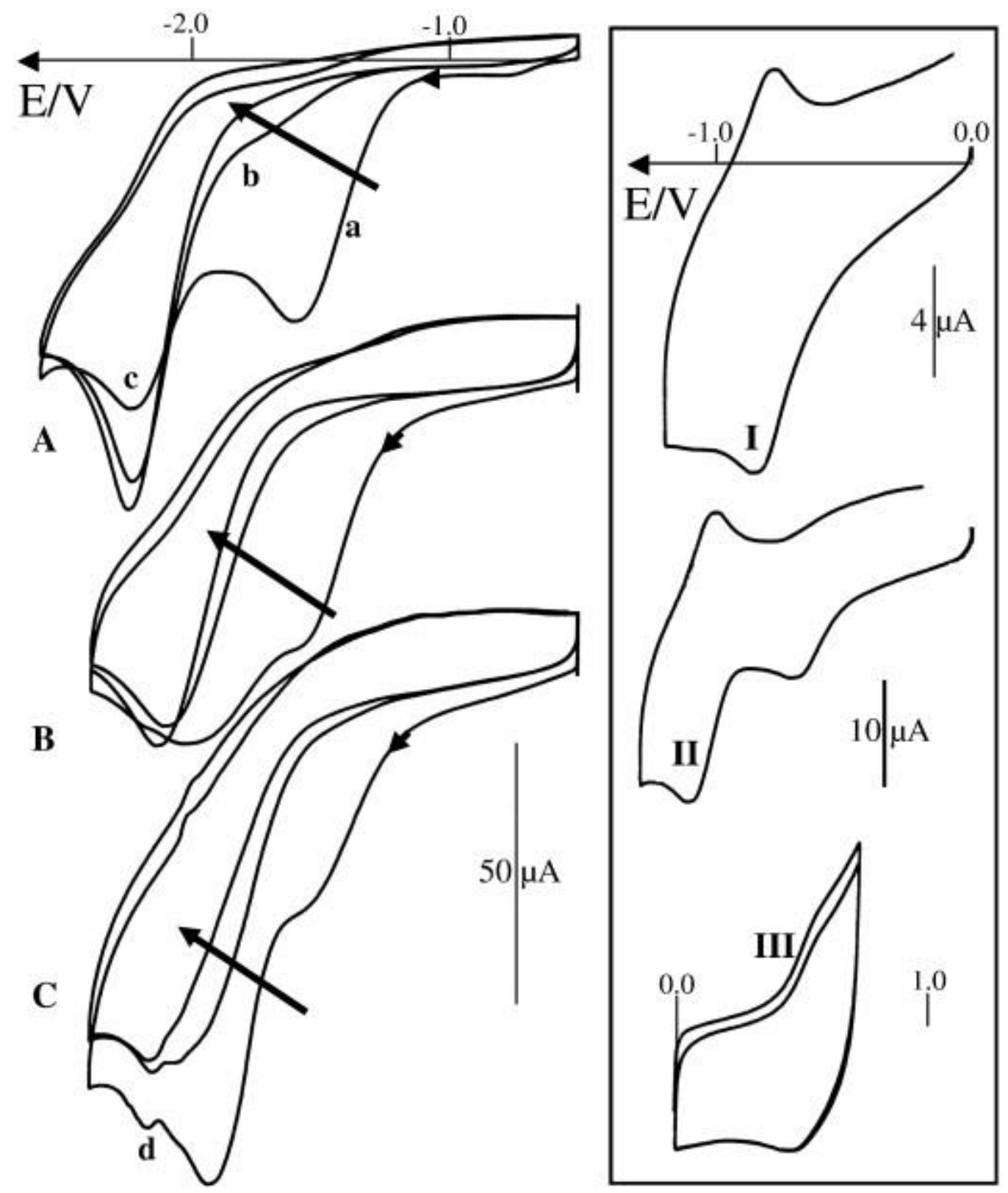

Fig. 2. Voltammetric analyses of GC electrodes (surface area: $7 \mathrm{~mm}^{2}$ ) modified by contact with air after a charge in DMF containing $0.1 \mathrm{M} \mathrm{TBABF}_{4}$. Charge potential: $-2.25 \mathrm{~V}$.

Electrodes are rinsed with water for $1 \mathrm{~min}$ and then put in contact with different electrophiles RX. Voltammograms shown in A, B and C correspond to the reaction of the GC with 1iodooctane $\left(8.2 \mathrm{mmol} \mathrm{L}^{-1}\right)$ in DMF + TBABF 4 . Scan rate: $50 \mathrm{mV} \mathrm{s}^{-1}$. A) Smooth GC electrode. Amount of charge: $8.5 \times 10^{-3}$ C. B) GC electrode mechanically covered by a thin layer of graphene. Charge: $2 \times 10^{-2} \mathrm{C}$. C) GC electrode mechanically covered by natural graphite. Charge: $2.5 \times 10^{-2} \mathrm{C}$. In the inset, three examples of surface modification of GC by RXs $\left(10^{-2} \mathrm{M}\right.$ in propylene carbonate for $5 \mathrm{~min}$ ) after charging and contact with air.

Sonication for 2 min. (I): 2-bromomethylanthraquinone. II): 4-nitrobenzylbromide. III): $\omega$ iodohexyl-1-ferrocene. 
The reactivity of surface peroxides could be shortly exemplified in the inset of Figure 2. In I, anthraquinone (reduced before the O-O scission) could be immobilized. On the contrary, in II, 4-nitrobenzyl bromide reacts with the surface, but the scission (due to the electron withdrawing effect) occurs before the reduction of the nitro-aryl group. Lastly, in III, ferrocene could be attached which permits to verify the two methods developed in $\$ 3.1$. and $\S 3.2$. are equivalent, although the second recipe is easier and more general.

\section{Conclusion}

For the first time, the electrophilicity of di-oxygen toward cathodically charged carbons was evidenced. It is clear, however, that such kind of affinity had been shown by Kharasch (1954) towards Grignard reagents, similarly leading to peroxides, but the present contribution allows the electrochemical peroxidation of many varieties of carbons under very simple conditions. Moreover, the versatility of the method makes possible the trivial conversion of the O-O bond into hydroxylates by simple cathodic (two-electron) scission of peroxides. From this, it appears that the poly-hydroxylation of carbon surfaces can be employed for facile functionalizations as explicated in Scheme 1, reactions 5 and 6.

Acknoledments. The author warmly acknowledges Pr. V. Jouikov for his help and kind interest in this work.

\section{References}

[1] H. Lund, O. Hammerich, "Organic Electrochemistry", 4th ed., M. Dekker, New York, Basel, 2001.

[2] H. J. Schäfer in "Comprehensive Organic Synthesis", Vol. 3 (Eds.: B. M. Trost, I. Fleming), Pergamon Press, New York, 1991, p. 633.

[3] T. Shono, "Electroorganic Synthesis", Academic Press, San Diego, 1991.

[4] R. L. McCreery, Chem. Rev., 108 (2008) 2646.

[5] G. M. Jenkins, K. Kawamura, Nature, 231 (1971) 175.

[6] P. J. F. Harris, Philosophical Magazine, 84 (2004) 3159.

[7] J. Pinson, F. Podvorica, Chem. Soc. Rev. 34 (2005) 154.

[8] J. Simonet, Electrochem. Commun., 13 (2011) 1417.

[9] V. Jouikov, J. Simonet, Electrochem. Commun., 15 (2012) 93. 
[10] V. Jouikov, J. Simonet, ChemPlusChem., 78 (2013) 70.

[11] P. Bernier, S. Lefrant, Le carbone dans tous ses états, Gordon and Breach Science Publishers, Amsterdam, (1997), and references cited.

[12] V. Jouikov, J. Simonet, Langmuir 28 (2012) 931.

[13] T.G. Brilkina, V.A. Shushunov, "Reactions of Organometallic Compounds with Oxygen and Peroxides", Chemical Rubber Company Press, Cleveland, Ohio, (1969).

See also: M.S. Kharasch, O. Reinmuth, "Grignard Reactions of Nonmetallic Substances”, Prentice-Hall, Englewood Cliffs, N.J., (1954) 1264.

\section{Caption for Figures}

\section{Figure 1}

A) And B), voltammetry of 1-iodoalkanes at GC electrodes in $\mathrm{AN}+\mathrm{TBAPF}_{6}$ Scan rate: 50 $\mathrm{mV} \mathrm{s}^{-1}$. Surface areas of used electrode: $0.8 \mathrm{~mm}^{2}$. Exhibited scans are those of 1-iododecane in $\mathrm{A}\left(8.5 \mathrm{mmol} \mathrm{L}^{-1}\right)$ and 1-iodododecane in $\mathrm{B}\left(5.6 \mathrm{mmol} \mathrm{L}^{-1}\right)$. Such voltammetric responses are only obtained when the potential (-1V) is applied concomitantly with the start of the argon bubbling until a total de-aeration of the electrolytic solution.

C) Voltammetry of $\mathrm{Fc}_{-} \mathrm{C}_{6}-\mathrm{I}\left(7.4 \mathrm{mmol} \mathrm{L}^{-1}\right)$ as electrophile in $\mathrm{DMF}+\mathrm{TBABF}_{4}$. Apparent surface area of electrodes: $7 \mathrm{~mm}^{2}$. In $\mathrm{C} 1$, electrode response in the absence of di-oxygen in the solution. In $\mathrm{C} 2$, the same solution with a partial pressure of di-oxygen. In $\mathrm{C} 3$, anodic response in a solution free of $\mathrm{Fc}_{-} \mathrm{C}_{6}$-I after one single scan between 0 and $-1 \mathrm{~V}$.

\section{Figure 2}

Voltammetric analyses of GC electrodes (surface area: $7 \mathrm{~mm}^{2}$ ) modified by contact with air after a charge in DMF containing 0.1 M TBABF 4 . Charge potential: -2.25 V. Electrodes are 
rinsed with water for 1 minute and then put in contact with different electrophiles RX. Voltammograms shown in $\mathrm{A}, \mathrm{B}$ and $\mathrm{C}$ correspond to the reaction of the $\mathrm{GC}$ with 1-iodooctane $\left(8.2 \mathrm{mmol} \mathrm{L}^{-1}\right)$ in $\mathrm{DMF}+\mathrm{TBABF}_{4} . \mathrm{Scan}_{\text {rate: }} 50 \mathrm{mV} \mathrm{s}^{-1}$.

A) Smooth GC electrode. Amount of charge: $8.5 \times 10^{-3} \mathrm{C}$.

B) GC electrode mechanically covered by a thin layer of graphene. Charge: $2 \times 10^{-2} \mathrm{C}$.

C) GC electrode mechanically covered by natural graphite. Charge: $2.5 \times 10^{-2} \mathrm{C}$.

In the inset, three examples of surface modification of GC by RXs $\left(10^{-2} \mathrm{M}\right.$ in propylene carbonate for 5 minutes) after charging and contact with air. Sonication for 2 min. (I): 2bromomethylanthraquinone. II): 4-nitrobenzylbromide. III): $\omega$-iodohexyl-1-ferrocene.

\section{$\underline{\text { Scheme } 1}$}

Main reactions provoked by contact of oxygen to charged carbon cathodes in the presence of alkyl iodides RIs as electrophiles 